\title{
Lithospheric Dynamics of China
}

\author{
by Ma Xingyuan
}

The very heterogeneous lithosphere of China can be described in terms of the motions of eight active subplates and 17 subsidiary "tectonic blocks" and their relationship with deep-seated processes. This article summarizes a recent compilation undertaken as part of the International Lithosphere Program and reviews the characteristics of these units, their neotectonic setting, their motions and the recent tectonic stress fields and seismicity of China. Though other schools of thought in China interpret the geology of the region in less mobilistic terms, the focus here is on intraplate phenomena, which pose some major problems for plate tectonic models. (Ed.)

\section{Introduction}

China is one of the most active tectonic areas in the world, and numerous earthquakes occur over more than half of the country. In the past 20 years, a wealth of new data from all branches of earth sciences and from every province in China has been accumulated. Accordingly, in 1982 the State Seismological Bureau established a Lithospheric Dynamics Atlas Project to produce a comprehensive set of maps combining geological, geophysicai, geochemical and grodetic data. The recently published $1: 4,000,000$ Lithospheric Dynamics Map of China and Adjacent Seas (Ma, 1987 ) is an integral part of the Atlas project. Active subplate and tectonic blocks (Fig. I and Table 1) are used as the basic units to describe the intraplate dynamies that form the main focus of this review.

\section{Neotectonic Setting}

Three elements make up the neotectonic setting of China. First, there is the stable Siberian eraton in the north. second, to the southwest is the site of the continental collision of the Indian plate with the Eurasian plate about 50 to 40 "la ago (Molnar and Tapponnier, 1975). This collision and the further continuous penetration of the Indian plate have led to the building of high plateaus and mountain ranges and the formation of thrust belts, large strike-slip faults, and widespread compressional and extensional basins. These have caused profound changes in the configuration and relative motions of the various blocks that compose the lithosphere of China.

The third element occurs on the eastern side of China, where the most important tectonic events were the formation of island-arcs along the western Pacific in late Mesozoic time, and the development of a marginal sea system in the Paleogene (as evidenced by the initial opening of the Sea of Japan and the South China Sea), which continued into Neogene time. Taiwan has been greatly modified tectonically by the convergence of the Philippine Sea plate with Asia along the Ryukyu-Taiwan-Luzon Are system during the Tertiary. Subsequent migration of the subduction zone to the collision suture of the island's Longitudinal Valley in Late Miocene time gradually steepened the Benioff zone to a vertical position by Pliocene time and has kept active since then. The latest phase of convergence of the Philip- pine Sea plate with Taiwan occurred in Late Pliocene to Pleistocene time as a north-dipping East-Hualien subduction zone at latitude $24^{\circ} \mathrm{N}$, near the southern end of the Ryukyu Arc (Juan et al., 1983; Wu, 1979). These continental margin events have had important effects on the lithospheric dynamics of eastern China.

The large scale, great variety, rapid rates and young age of intracontinental deformation, the strong shallow seismicity and active sub-lithospheric processes all make China, and particularly the Qinghai-Tibetan plateau, North China and Taiwan, the best place to study intraplate dynamic processes.

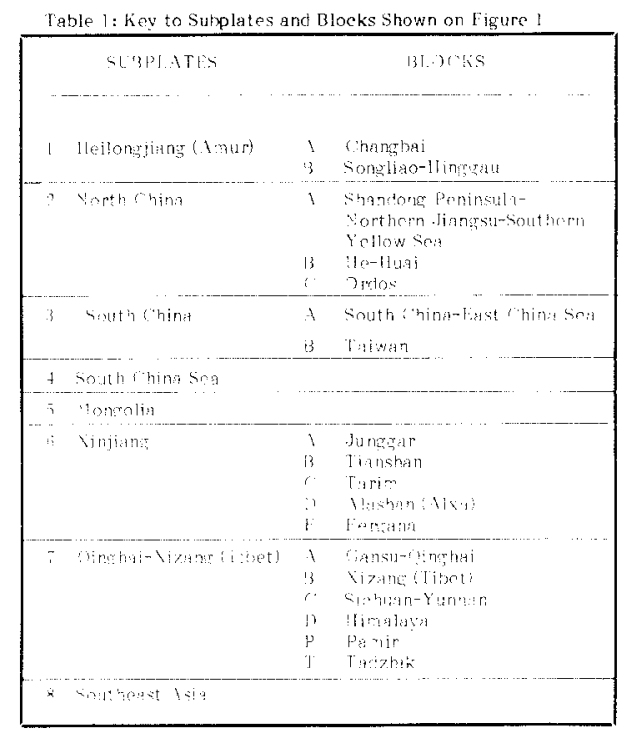

Active Subplates and Tectonic Blocks

China and neighbouring areas can be subdivided into eight subplates and 17 blocks (Fig. 1), the boundaries of which are defined in several ways. They are usually characterized by broad belts along which movement is distributed over several active faults or graben systems tens or even hundreds of kilometres in width (Fig. 2). Belts of earthquakes, particularly strong ones, faithfully outline many subplate and block boundaries. Zones of relatively high concentration of strong earthquake epicenters are prominent (see $\mathrm{Fig}$. 5) and indicate the presence of a mosaic of subplates and blocks. Broad zones of active faults and rifts or graben systems are common and are sensitive indicators of deepseated processes. Geophysical variations such as steep gradients in gravity anomalies, together with rapid changes in crustal and lithospheric thickness, and the unity of dynamic features within subplates also help to define these subdivisions. 


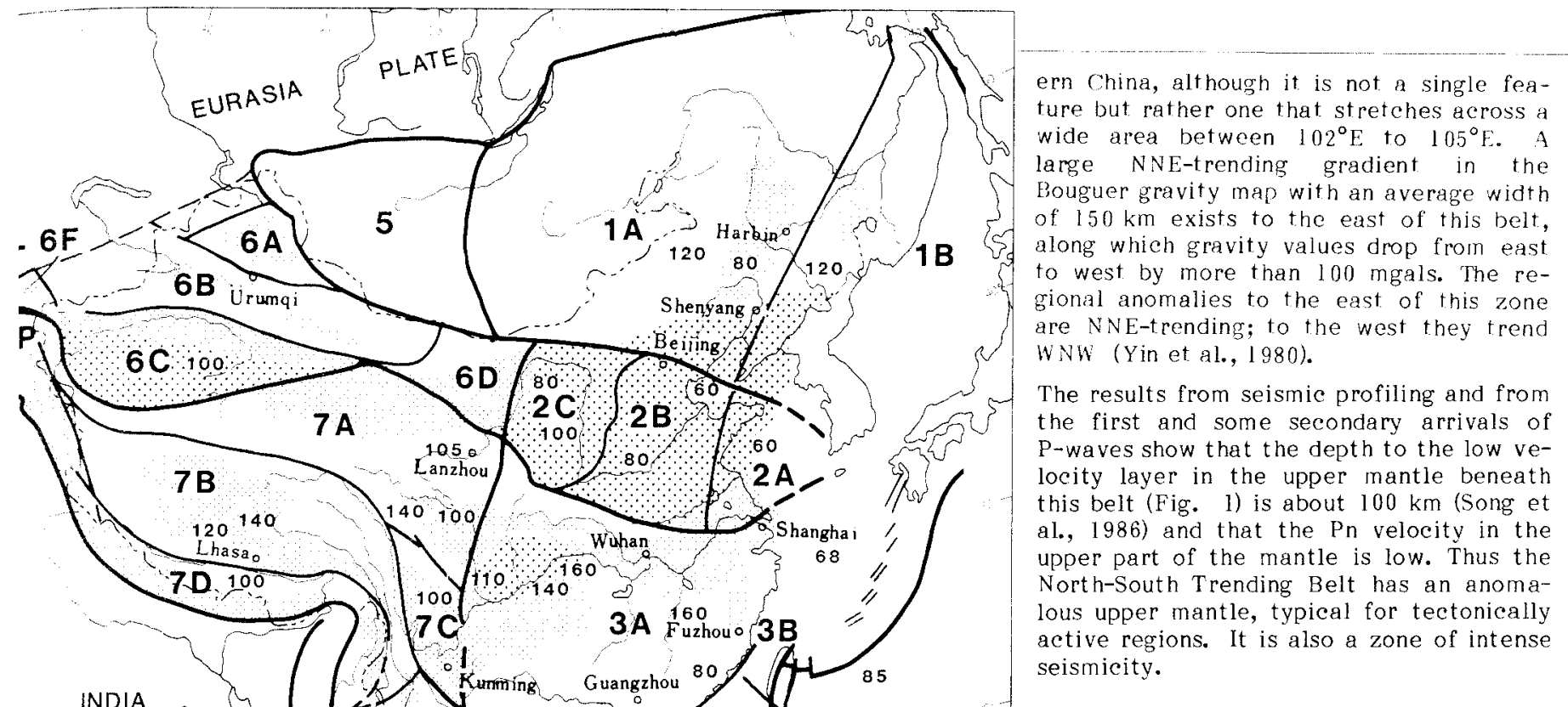

ern China, although it is not a single feature but rather one that stretches across a Bouguer gravity map with an average width of $150 \mathrm{~km}$ exists to the east of this belt, which gravity values drop from eas gional anomalies to the east of this zone are NNE-trending; to the west they trend WNW (Yin et al., 1980). the first and some secondary arrivals of this belt (Fig. 1) is about $100 \mathrm{~km}$ (Song et al., 1986) and that the Pn velocity in the upper part of the mantle is low. Thus the North-South Trending Belt has an anomaregions. It is also a zone of intense

Figure 1: Active plates, subplates and tectonic blocks (named on Table 1) of china and neighbouring areas. 1- Boundaries of subplates (thicker lines) and hlocks; 2- Age of Precambrian basement (coarser stipple - early Proterozoic, finer stipple middle to late proterozoic); 3Lithospheric thickness (in $\mathrm{km}$ ).

Fiqure 2: Relative motion vectors With rates in $\mathrm{mm} / \mathrm{yr}$ ) of the active plates, subplates and tectonic blocks of China and neighbouring areas. I to 4-Active plate boundaries (1-divergent, 2- subduction, 3- collision, 4- transform); 5subplate and block boundaries; 6Intraplate grabens and rifts; 7Motion vectors of subplates and blocks relative to the Eurasian plate.

The depth to which these boundaries exlend into the lithosphere may be deternined by examining the free-air gravity anomaly maps of China, because they most clearly reflect density variations within the lower crust and upper mantle (viei et al., 1981). The boundaries are well reflected by the major trends in the Pree-air anomaly maps (see Figs. 3 and 4 of "Ta, 1987).

\section{Some Examples}

iniferent subplates are characterized by distinct geophysical features as shown by their crustal and upper mantle structure and regional geophysical fields. We have taken the North-South-Trending Belt along the western edge of the North China and South China subplates (Fig. 1) as the boundary between eastern and west-
PHILIPPINE

PLATE 
The ITe-lluai block of the Worth China subplate is a region where many reophysical studies of crustal structures have bcen conducted (e. . Liu et al., 1983: Sun et al., 1985). The erustal thickness increases from beneath the North China plain and Shansi graben to the surrounding mountains from $29 \mathrm{to}+4 \mathrm{~km}$. The middle crust usually consists of alternatiog layers of lower and higher velocity; the thickness of the lower crust is senerally about $10 \mathrm{~km}$ under the North China plain and $15 \mathrm{~km}$ under the Shanxi highland. There is a transition zone berween erust and mantle in which the velocity varles from 6.4 to $7.6 \mathrm{~km} / \mathrm{s}$; the thickness of this trmasition zone is about $2 \mathrm{~km}$ under the North China plain and about $5-6 \mathrm{~km}$ thick under the surrounding mountains.

Inder the Bohai sea and central liebei, the Hoho forms large, elongated done-shaped upwarps that trend NE to NNE. The average crustal velocity of the North china subplate is comparatively low, with p-wave velocity of 6.21 $\mathrm{km} / \mathrm{s}$ and S-wave velority of $3.5 \mathrm{~km} / \mathrm{s}$. The results of magnetotelluric soundings (Liu, 1987) and the inversion of seismie data suggest that the lithospheric thickness also varies narkedly from about $60 \mathrm{~km}$ beneath the Bohai sea and about $80 \mathrm{~km}$ beneath the North China plain, to more than $120 \mathrm{~km}$ in the mountainous areas. The heat flow value in the North China plain is high, with the 1.6 HFU contour approximately following its margin, though the heat flow values inside the plain vary considerably.

The ordos block has a stable and "cool" rigid lithosphere about $120 \mathrm{~km}$ thick, with Pn value up to $8.2 \mathrm{~km} / \mathrm{s}$. Bouguer gravity anomaly gradients can be found along its northern, western and eastern mangins. The formation of graben systems along its peripheral belts was probably associated with the upwelling of mantle material alons structurally varying zones in the lithosphere (Deng and You, 1985).

The Taiwan bloch of the south china subolate is the youngest and most active plate margin orogen formed by arc-continental collision. The crust of the main part of the island is very similar to continental crust, with a thickness of about $40 \mathrm{~km}$ beneath the Central Range thinning westward to about $30 \mathrm{~km}$, where the Hoho is warped upward. The orust under the coastal Range is peculiar, with a

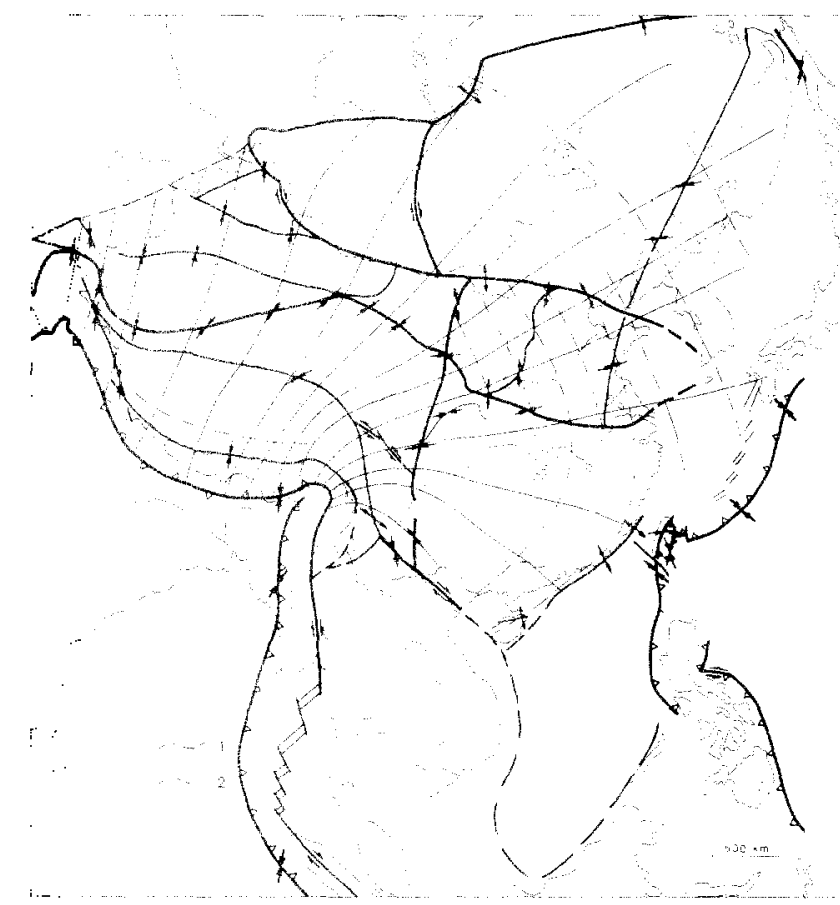

Figure 3: Pegional tectonic stress field for china and neighoming areas. 1- Trajectories for maximum principal (compressiunal) stress axes; 2- Trajectories for minimum orincipal (tensile) stress axes. thickness of about $20 \mathrm{~km}$. The upper mantle $\mathrm{p}$-wave velocity below the island is $7.75 \mathrm{~km} / \mathrm{s}$, which is typical for tectonically active regions such as the Japanese Island arc or the Basin and Range province of the western U.S. A. (Wu, 1979).

The Qinghai-Xizang subplate is characterized by thick crust and relatively thin lithospheric mantle. The former is multilayered, with a low velocity layer in the upper and lower parts. The average velocity of the crust is the lowest of all the subplates in China with P-wave velocity of $6.23 \mathrm{~km} / \mathrm{s}$ and S-wave of $3.45 \mathrm{~km} / \mathrm{s}$. According to Feng and Zhou (1985), the Q-value beneath the Xizang plateau is less than half of the global average, indicating that the plateau is a plastic block with rather low viscosity. The southern Xizang and western Yunnan regions have higher heat flow and geothermal gradients, which suggest favourable conditions for partial melting and the occurrence of heat reservoirs in the crust (Shen et al., 1985). According to Feng (1985) the crustal density of the Qinghai-Xizang subplate is comparatively low (about $2.84 \mathrm{~g} / \mathrm{cm}$ ), whereas the density of the upper mantle is remarkably high $(3.40-3.65 \mathrm{~g} / \mathrm{cm})$.

\section{Block Motions and Recent Tectonic Stresses}

The motion vectors of subplates and blocks are shown in Figure 2 as relative motions between adjacent units and between single units and the Eurasian plate (Siberian craton). The former are expressed as the horizontal projection of the slip vectors, and the average slip rates are calculated from the relative motion of the various boundary frults. These data are shown in Figure 2 by pairs of arrows market on the boundaries, and from them the relative motion between adjacent blocks can be determined (Ding and Lu, 1986, for western China; Molnar and Deng, 1984, for eastern China; and Zonenshain and Savostin, 1981 for western China, with supplementary data). Although these determinations cannot be considered as absolutely accurate, they do permit an approximate assessment to be made of the kinematic pattern of block interaction and the state of the current regional stress field.

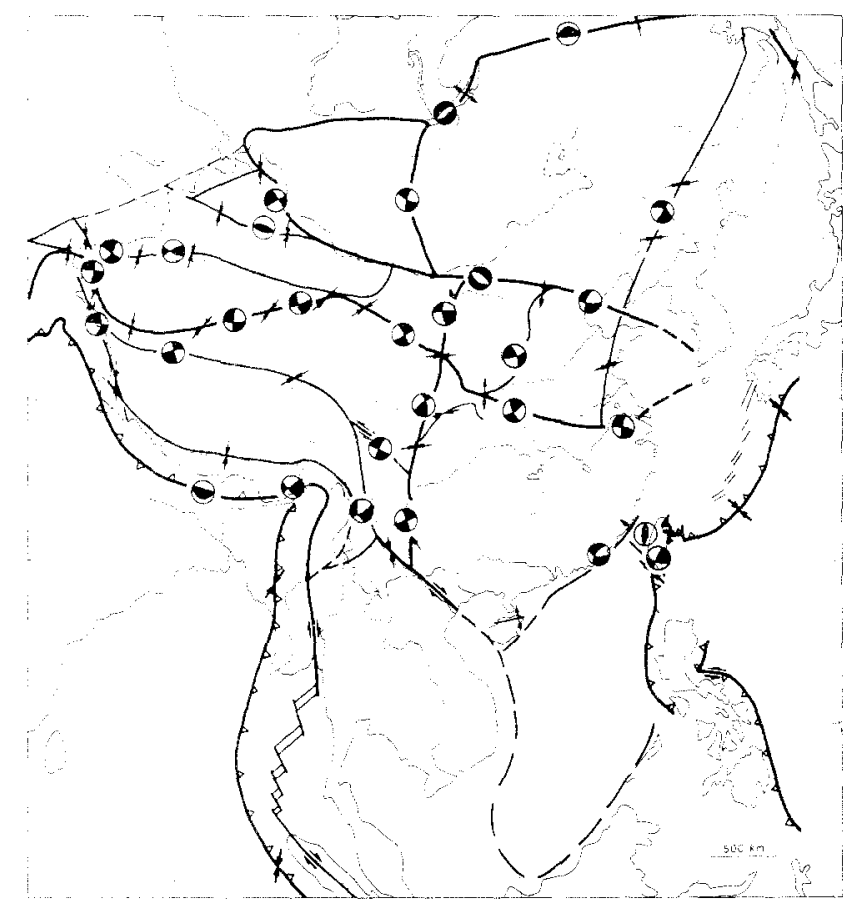

Figure 4: Earthquake focal mechanism solutions along boundaries between the different subplates and blocks. 
The movement pattern of the subplates and blocks in western China suggests that the collision and further convergence of the Indian with the Eurasian plate is the most plausible driving mechanism involved. The strong impedance exercised by the Pamir block caused the other blocks of western China to rotate and move easterly. The rates of movement of the various blocks with respect to the Eurasian plate decrease towards the north, with the central portion of the Junggar block moving at a rate of only $3 \mathrm{~mm} / \mathrm{a}$, which is close to the absolute rate of motion of $4 \mathrm{~mm} / \mathrm{a}$ calculated by Minster and Jordan (1978).

The subplates and blocks in eastern China tend to fan out under the eastward compression exerted by the movement of the blocks in western China. There are, however, different dynamic settings on their east side in the western Pacific. These forces on both sides of these subplates and blocks have combined to increase the rate of eastward motions from north to south.

The recent tectonic stress field in China has been studied by many authors (Yan et al., 1979; Deng et al., 1979; $\mathrm{Wang}$ and Xu, 1985; Shi et al., 1985; Otsuki, 1985; Li et al., 1985; Li and Liu, 1986), and a regular and unified stress pattern has been obtained ( $\mathrm{Fir} .3$ ). The framework of this stress field is one involving maximum principal stress trajectories trending nearly NS to NNE from the Oinghai-Xizang to Xinjiang subplate and thence bending and diverging eastward. They curve around the Assam vortex of the Indian plate and trend south-east ward in the Sichuan-Yunnan block.

ivang and $\mathrm{Xu}$ (1985) derived the compressional (P), intermediate (B) and tensile (T) principal stress axes for composite fault plane solutions in 23 regions of eastern china. They used the grid point trial method, based on the data of l' wave first motions for 1211 micro-eart hquakes $(?, \mathrm{~F}, 1.0)$ scattered throughout eastern China from 1973 to 1982. The results (fig. 4) indicate that east of $105^{\circ} \mathrm{E}$ the average $P$ axis direction remains basically horizontal, radiating from the central inland area eastward towards the coast, and switching from NE-trending in the north to a nearly E-W or $S E$ trend in the south. The average $T$ axes are horizontal and form an arcuate, convex eastward pattern that varies regularly from north to south. Except in the Liupanshan region, the $\mathrm{T}$ axis remains horizontal.

The orientation of principal stress axes in most parts of eastern China implies that strike-slip faulting predominates (see Fig. 6), particularly in North China and the coastal belt of southeast China. However, fault-plane solutions of earthquakes in Taiwan indicate predominant thrust faulting with a strike-slip component.

\section{Distribution of Earthquake Epicenters}

Iistorical and instrumental data show that earthquakes are spread diffusely over more than half of China, with the Heilongjiang, South China and South China Sea subplates being regions of low seismicity (Fig. 5). This territory, together with neighbouring areas of U.S.S.R. and Mongolia, comprises the largest continental mass on Earth in which numerous and large earthquakes occur. Among the earthquakes whose epicenters are shown on Figure 5 are 261 that occurred before 1900 and are recorded in historical documents, and $41 \mathrm{l}$ that took place between 1900 and 1985 and were recorded instrumentally. Altogether there are 23 of $M>8,133$ of $M 7.0-7.9,413$ of M6.0-6.9, and 103 of M5. 0-5.9.

The North China subplate has been a highly active area both in the recent past and at present. To date there have been six earthquakes of $M>8,11$ of $.17-7.9$ (the 1976 M7.8 Tangshan earthquake being the largest of this century) and 43 of M6.0-6.9. The b value is estimated to be 0.62 (Shi et al., 1982). Earthquake hypocenters are scattered throughout the region, but large earthquakes are mainly concentrated on major fault belts such as those along the western and northern margins of the subplate and along the Fon-ivei graben system separating the blocks.

The Taiwan block is much more active than other parts of China. The earthquake frequency here is very high, the recurrence interval short and the intensity large, but there are few earthquakes with high magnitudes. The seismic features of western Taiwan are similar to those in the coastal area of southeastern China, but many more earthquakes of $\|>6$ have occurred since the beginning of this century. There are small but deeper earthquakes in northern Taiwan, which demonstrate that a Benioff zone may exist in that region at present ( $\mathrm{Nu}, 1979$ ).

The Qinghai-Xizang subplate is also a very active region, with the highest earthquake frequency, spatial concentration of earthquakes, and magnitudes. Of the earthquakes recorded here since 1900 , two were of $M>8,45$ of $M 1=7.0-7.9$, and 236 of $116.0-1.9$; the b value is 0.79 .

Strong earthquakes in the Xinjiang subplate are mainly distributed along the southern and northern sides of the Tianshan. Features of seismicity along the Altay are similar to those in West Mongolia. The western margin of the Xinjiang subplate is marked by a NE-trending seismic belt with strong earthquakes near Kashi, not far from the western syntaxis of the Himalayan are.

Almost $99 \%$ of the earthquakes in China have shallow crustal sources. Their depth distribution and degree of activity seem to be closely correlated with the crustal thickness and structure, with the existence of high conductivity and low velocity layers in the erust, and with heat flow values. All of this shows significant regional depen-

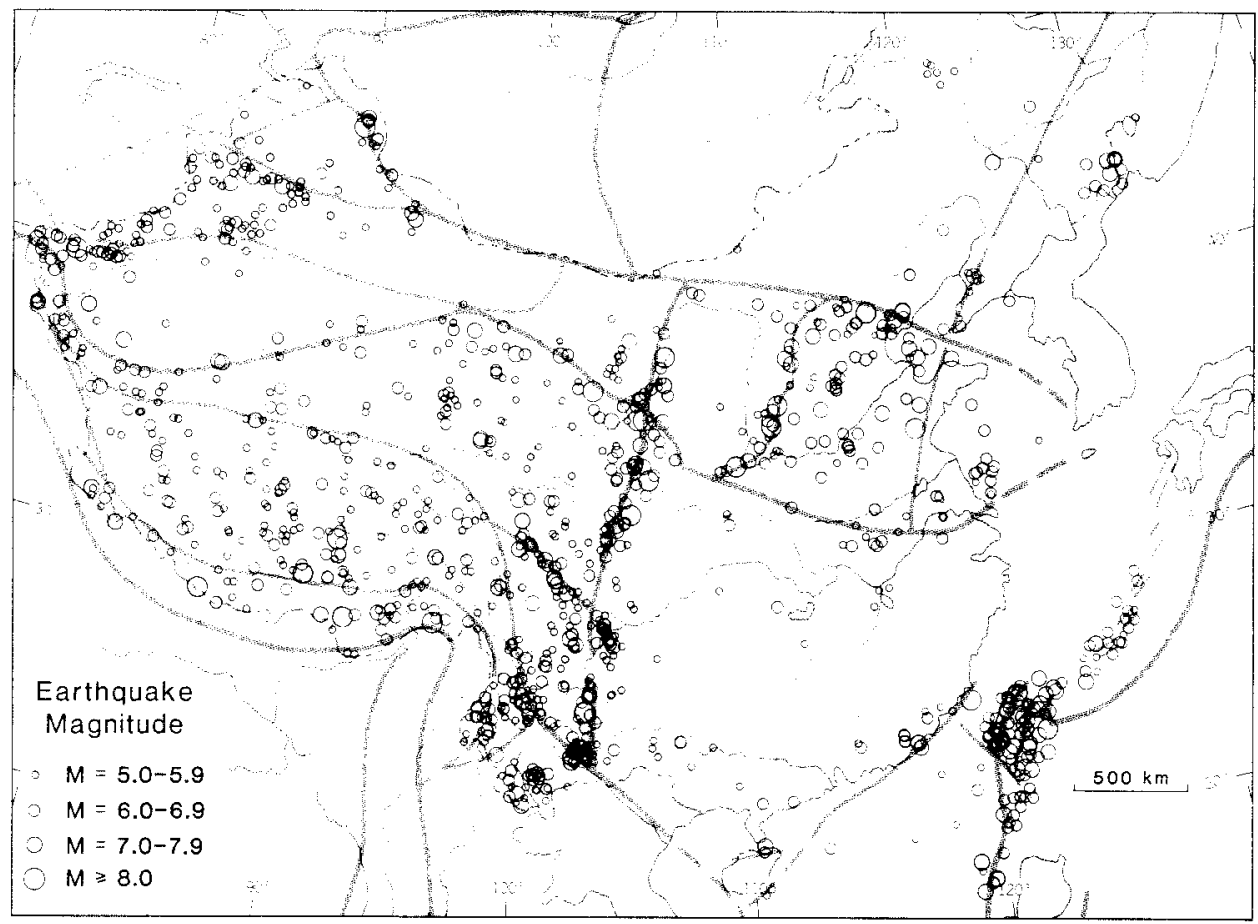

Figure 5: Epicenters and magnitudes of 672 strong earthquakes occurring between $780 \mathrm{BC}$ and $1985 \mathrm{AD}$. 

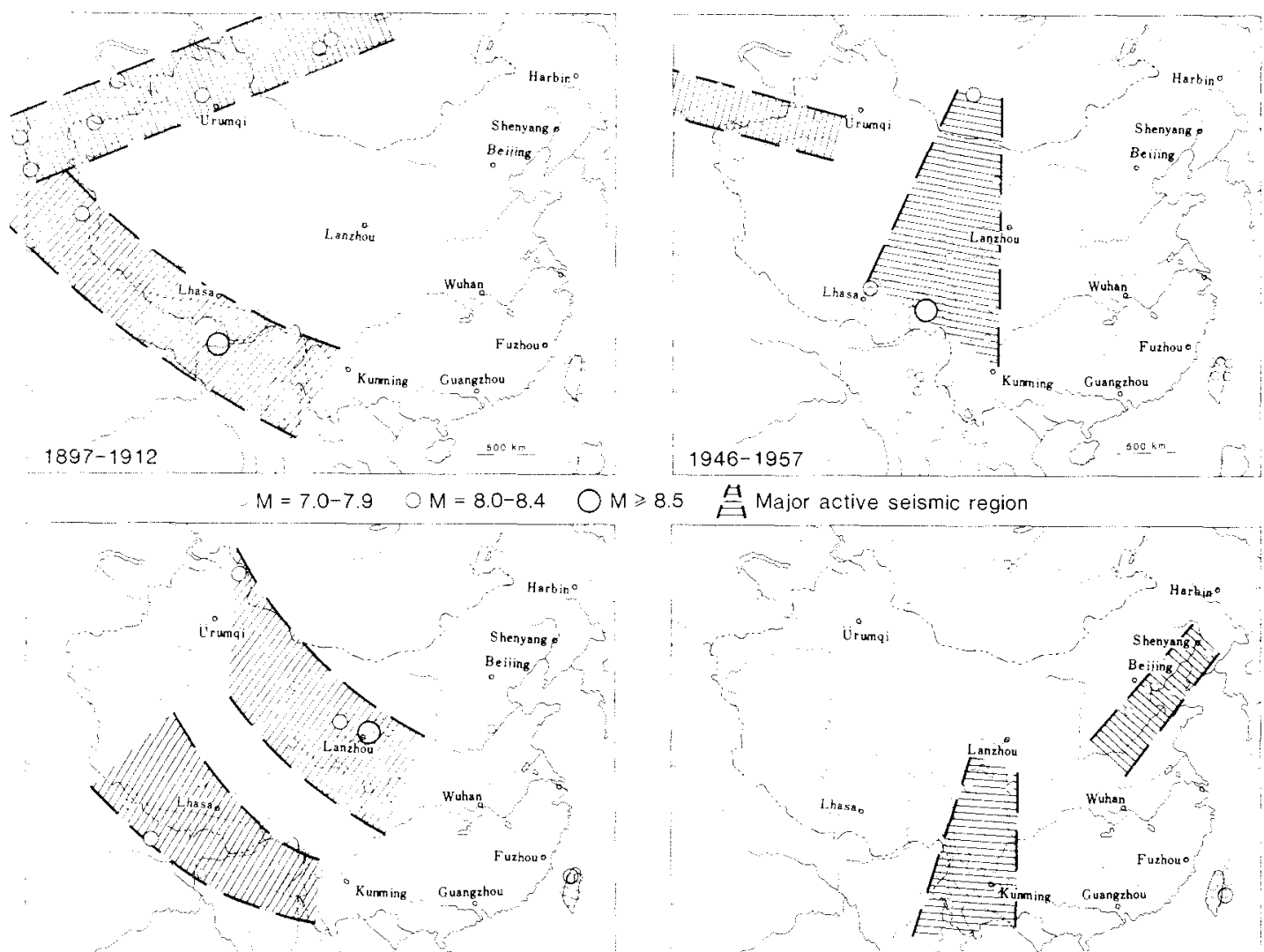

$1920-1937$

Figure 6: Spatial distribution and magnitudes of strong earthquakes in chind between 1897 and 1980.

dence. However, among earthquakes with $M>6.0$ in China, more than $90 \%$ occur at depths of $10-25 \mathrm{~km}$, referred to as the "seismogenic layer" (Ma and Xue, 1983). This phenomenon supports the idea that a brittle "lid" with hypocenters concentrated towards its base overlies a more ductile layer in the middle-lower crust.

\section{Modern Seismicity in Time and Space}

Since the beginning of this century, the worldwide seismic network and the national seismic network of China have detected earthquakes with $M>6.7$ over all of China. The variations in time and space of high seismicity in this period may reflect present-day changes in the stress field. The distribution of strong earthquakes is rhythmical with periods of intense seismicity alternating with periods of quiescence.

Figure 6 shows the spatial distribution of strong earthquakes in episodes, each of which was dominated by earthquakes along one or two seismic zones. The location of these varied widely from episode to episode (Ma et al., 1984), illustrating that current stress fields change rapidly and at a large scale. For instance, the fourth active episode of this century began in 1966 and ended in 1976, lasting about 11 years. There were no earthquakes with $M>7$ in the following nine years, a relatively quiescent period. The 1985 Wuqia earthquake of 17.4 in Xinjiang may imply that China has entered another seismic episode. However, it is still not possible to forecast the principal region and tectonic trend of this new phase.

\section{Neotectonic Deformation}

The pattern and style of neotectonic deformation is closely related to the motions of plates and subplates. It may involve complex deformational (orogenic) processes. Neotectonic deformation may also occur as a broad warping of the Earth's surface (epeirogeny) expressed, for example, by a
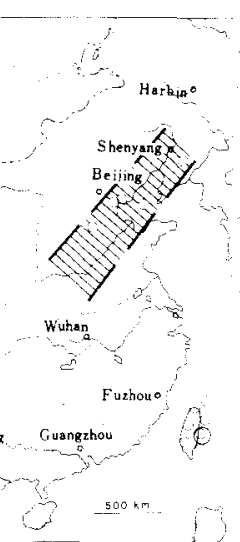

$3000-4000 \mathrm{~m}$ uplift of the Himalayas and the Xizang plateau, since the Late Pliocene and a rise of $2200-3000 \mathrm{~m}$ of the Tianshan mountains since the end of the Tertiary.

Intraplate neotectonic deformation can be modelled with the as sumptions that the subplates and blocks are all moving, some faster than adjacent ones. Thus their mar gins can be defined in terms of leading, lateral and trailing margins. In principle, for the faster moving subplates or blocks the leading edge will be under compression, the lateral edge will be under dominant horizontal shear and the trailing edge will be under tension. For example the Heilongjiang sub-plate moving away from the Eurasian plate contributes to the opening of the Baikal rift in Siberia and the Hulun Lake graben in the Heilongjiang subplate. Similarly, the Jilantai-Yinehuan graben system developed along the divergent northwestern flank of the North China subplate.

No graben systems or rifts formed at the trailing edges of the subplates and blocks in western China, where the effect of Indian and Eurasian collision is very strong (Tapponnier et al., 1986). The overall deformation here resulted in $\mathrm{N}-\mathrm{S}$ crustal shortening, compressional folding, thrusting, strikeslip faulting, and in vertical crustal thickening, crustal stacking, mountain building, plateau formation and basin development. Another effect was an eastward crustal flow, with the development of arcuate tectonic belts along the length of the eastern margin of the Qinghaj-Tibet subplate (i.e. the North-South Trending Belt described earlier). These belts include from south to north, the Sanjiang arcuate belt, the Kunlun-Bayan Har belt, and the Qilian* Liupanshan belt. The thickened crust would have tended to spread under gravity, in a direction not necessarily parallel to the regional plate movement vector, a situation giving rise to structures whose orientation and deformation rate appear unrelated to regional movement.

Thus the various structural elements are related and the model explains the different structures in terms of a dynamic system. Deformation has occurred in progressive stages, each successive one overprinting its predecessor. Decoupling may occur between each stage, and block rotation may contribute significantly to the overall intraplate displacement (Figs. 7 and 8 ).

Freund (1970), Ron and co-workers (1984), and others have shown that rotation of blocks and strike-slip displacements are two different but contemporaneous aspects of a single deformational process. Where the fault spacing and net-slip can be constrained geologically, the angle of rotation can be determined, and paleomagnetic measurements can be used to test the sense and amount of rotation predicted by the model. Fault systems such as those in northwestern Yunnan, Altun Tagh and North China are particularly attractive sites for paleomagnetic and structural analysis. 


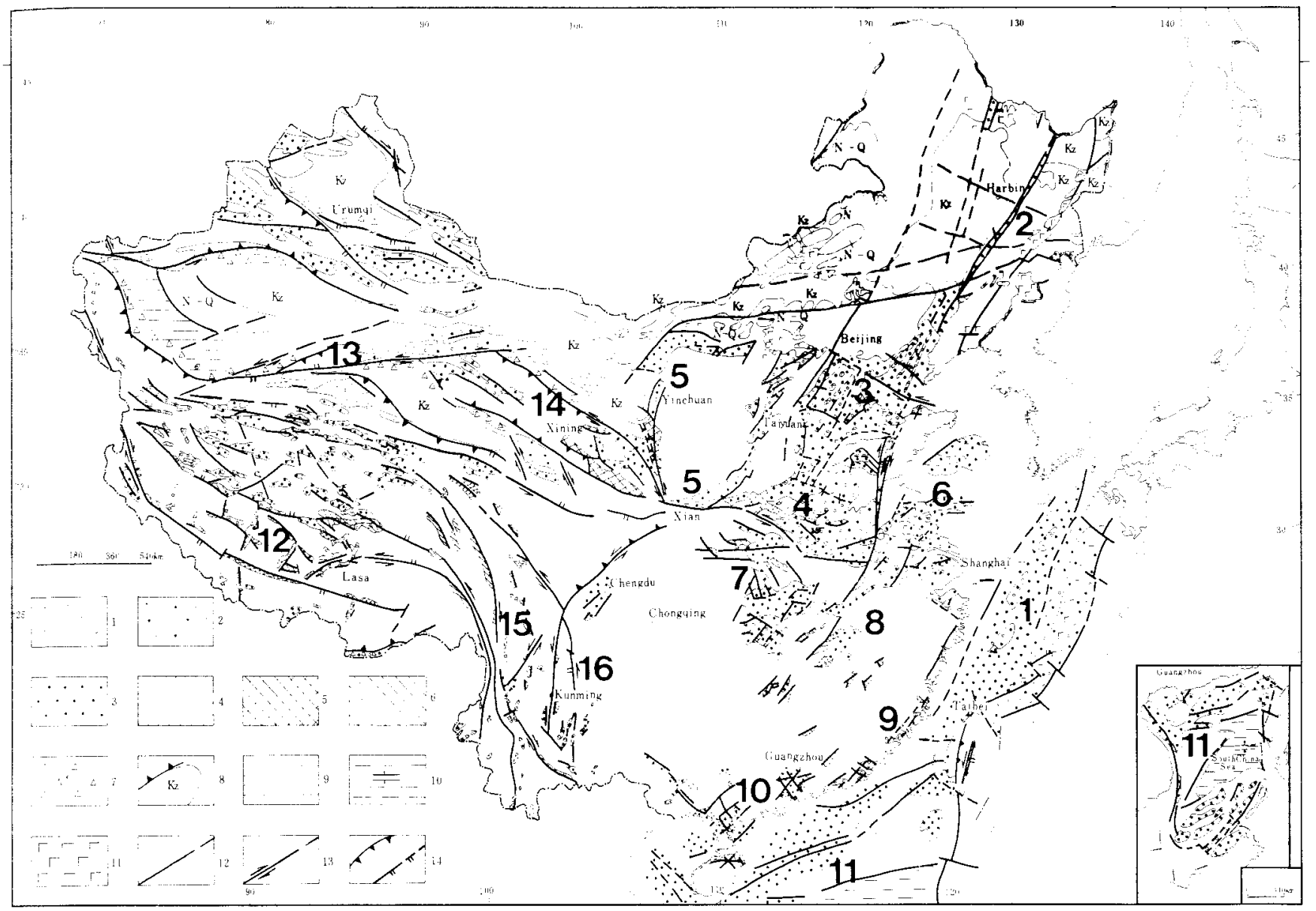

Figure 7: Cenozoic basins of China. After Ma and Su (1985) and Ma (1987). 1-Quaternary; 2- Neogene to Quaternary; 3- Paleogene to Quaternary; 4Neogene; 5-Tertiary; 6-Paleogene; 7- Pliocene to Quatemary molasse; 8- Compressional basins and depressions, with age of sedimentary infill; 9Eocene marine transgression; 10- Oceanic crust and spreading ridge; 11 - Cenozoic basalt; 12 to 14Faults: (12- strike-slip; 13- normal, some with strike-slip components; I4- thrust above, reverse below).
Bold numbers indicate Cenozoic graben systems: 1East China Sea and Okinawa Trough; 2- Yilan-YitongLower Liaohe rift belt; 3- North China; 4- HenanAnhui; 5-Ordos periphery; 6-Northern JiangsuSouthern Yellow Sea; 7- Jianghan-Nanxiang; 8Donting Lake-Lower Yangtse; 9- Fujian-Guangdong coastal system; 10-Guangxi-Gangdon; 11- South China Sea graben and oceanic basin; 12- NorthSouth-trending system of Xizang; 13- Altun Tagh; 14- Oilianshan; 15- Sanjiang; 16- AnningheXiaojiang.
Wu and others (1987, and personal communication) have explored the deformation kinematics of the fault domain in the western part of the sheared terrain of the SichuanYunnan block. They found that the convergence angle of the Quaternary extensional area indicated an average minimum $5.8^{\circ}$ rotation in a horizontal clockwise sense.

Conjugate fault sets are well developed in western China (Fig. 8). The original configuration must change with subsequent progressive deformation. The blocks or slivers in the conjugate strike-slip tectonic romains progressively rotate about a vertical axis in opposite directions away from the axis of maximum shortening, so that the angle between them is increased. Furthermore, distinct domains gradually evolve so that most of the slip occurs on one of the two fault sets. A typical example is the Altun Tagh system, which contains at least seven parallel ENE-trending leftlateral strike-slip faults. As the overall strike-slip motion continues during the neotectonic period, the slivers between them rotate clockwise toget her with the bounding faults.

For the North China subplate, Lu and Ding (1985) have argued that the Ordos block rotated in a horizontal counterclockwise sense, on the basis of a spherical trigonometrical analysis of the slip and strike directions of earthquakegenerated fault breaks and strike-slip faults. WNW-trending strike-slip faults of various length and displacement are common in North China, the best developed being the leftlateral strike-slip fault belts along the northern and southern margins of the North China subplate: the HetaoZhangjiakou-Bonglai and the Weihe-Shang Xien-Dan Feng northern Dabie fault belts. The subplate deforms in response to the left-lateral shear couple by right lateral slip on a NNE-trending fault set, which is associated with counter-clockwise rotation of the blocks between the transtensional faults (Fig. 8). These displacements and rotations led to $\mathrm{NNW}$ elongation and ENE compression, which is consistent with the seismic data and tectonic stress field. A detachment at the base of the seismogenic layer has been proposed on the basis of earthquake data.

\section{Concluding Remarks}

The collision between the Indian and Eurasian plates and the geodynamic conditions along the western Pacific margin have profoundly influenced the movement and deformation of the lithosphere in China. However, the state of stress in the lithosphere and the driving forees for the block motions are derived from different processes (Richardson et al., 1979; Turcotte and Schubert, 1982). Previous plate-tectonic models have successfully explained plate boundary tectonics and dynamic processes, but they do not account well for intraplate dynamics or for basic mechanisms of deformation within continents, such as those found in China. This remains a challenge for the earth sciences. 


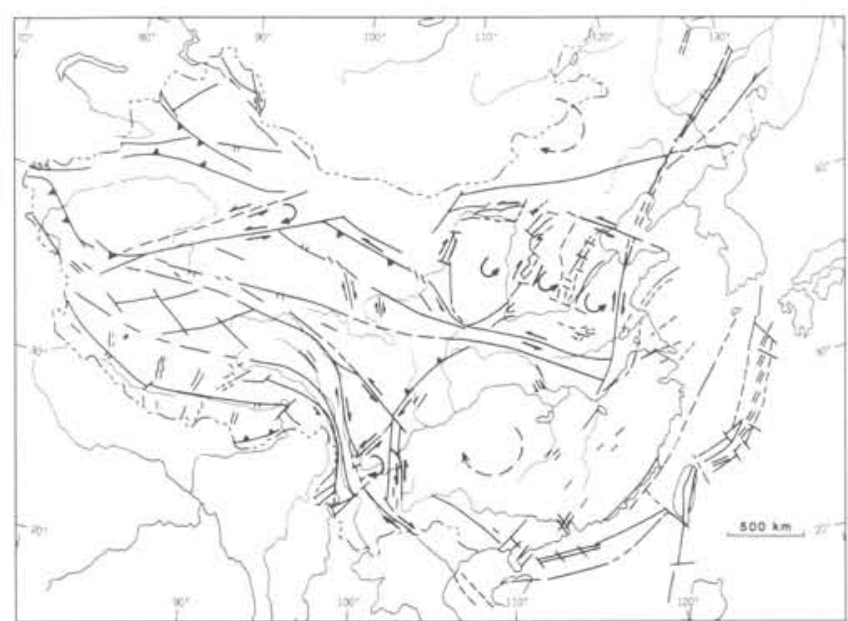

Figure 8: Major active faults of China and the rotation of blocks in northwestern Yunnan, Altun Tagh and North China.

For the present, the dynamic processes in the lithosphere may be considered simply as caused by the persistent interplay of internal heat and gravitational forces that produce convection within the Earth. This serves as the basic driving mechanism for plate and block motions, in which process the lithosphere itself takes an active part.
China presents scientific challenges in every field of geodynamics. Information about present-day movements and deformation of the lithosphere, as well as data on crustal stresses and density imbalances, provide sources for new research on the causes and modes of lithospheric dynamics. The results of this research will aid in the assessment, prediction and mitigation of geological hazards. It will also add to the knowledge needed for the protection of environment and for the exploration of mineral and energy resources.

Acknowledgement: The author wishes to thank his colleagues, the compilers of the Lithospheric Dynamics Map of China and Adjacent Seas.

Prof. Ma Xingyuan is based at the Institute of Geology in the State Seismological Bureau of China (P.O. Box 634, Beijing, China). A former student of Arthur Holmes, he is also Vice-President of the Geological Society of China, a member of the IUGS Commission on Tectonics, and Chairman of an ICL Subcommittee on the Himalayas and neighboring areas. Prof. Ma studies the tectonies and lithospheric dynamics of China, and he is compiling a major crustal profile for the Global Geoscience Transects project of the ILP.
References (* in Chinese with English abstract)

Deng Qidong, Zhang Yuming, Xu Guilin and Fan Futian, 1979. The tectonic stress field in China and its relation to plate movement. Physics of the Earth and Planetary Interiors, v. 18, no. 4, p. 257-273; Seismology and Geology (Chinese), v. I, no, 1, p. 11-23.

- Deng Oidong and You Huichuan, 1985. The structural activity and formation mechanism of the down-faulted basins amound Ortos block. Beseame on Recent Crustal Movement, v. L, p. 58-78.

-Ding Guoyu and Lu Yanchou, 1986. Preliminary study of state of present-day intraplate motions in China. Kexue Tongteo, no, 18, p. 1412-1415.

* Feng Rui, 1985. Crustal thickness and densities in the upper mantle beneath China - The results of three dimensional gravity inversion. Acta Seismologica Sinica, v. 7, no. 2, p. 143-157.

- Feng Rui and Zhou Hainan, 1985. Crustal Q-structure beneath the Tibetan plateau. Acta Physica Sinica, v. 28, Supplement 1, p. 174-184.

Freund, R., 1970. Rotation of strike slip faults in Sistan, southeast Iran. Journal of Geology. v. 78 , no. 2 , p. $188-200$,

Juan, v.C., Lo, H.J. and Chen, C.H., 1983. Geotectonics of Taiwan - an overview, In: Hilde, T.W.C. and Uyeda, S. (eds), Geodynamics of the Western Pacific-Indonesian Region. American Geophysical Union Geodynamics Series, v. 11, p. 379-386.

- Li Fangquan and Liu Guangxun, 1986, The present state of stress in China and related problems Acta Seismologica Sinica, y, 8, no, 2, P. 156-171.

-Lit Zhiqiang, Cao Xinling, Chen Jiageng, Liu Jianzhong and Zhang Zhi, 1985. Some considerations on recent tectonic stress field of China. Tectonophysics, v. 117, no, 1-2, p. 161-178.

* Liu Changquan, Yang Jian, $\mathrm{Li}$ Handong and Jiao Tiehua, 1983. Reinterpretation of the deep sounding data Baigl-zhuang-Fengnan-Fengning profile in Tangshan area. Acta Geophysica Sinica, v. 26, Supplement, p. 628-640.

Liu Guodong, 1987. MTS studies on the upper mantle conductivity in China. Pure and Applied Geophysies, v. 125, no. $2 / 3$, p. $465-482$

- Lu Yanchou and Ding Gouyu, 1985. The relative motions among intraplate blocks and Quater nary fault-basins around Ordos block, North China. Quaternaria Sinica, v. 6, no. 2, p. 124-131.

Lu Zaoxun, 1985. Progress of geophysical prospecting study on the deep structure of Haicheng earthquake area. Earthquake Research in Chine, v. 1, no. 1, p. 56-65.

- Ma Xingyuan and Su Jian, 1985. Taphrogenesis through the geological history of China. Research on Recent Crustal Movement, v. 1, p, 5-16.

Ma Xinzyuan and Wu Daning, 1987. Cenozoic extensional tectonies in China. Tectonophysics, 1., 133, no, 3/4, P. 243- 256 .

Ma Xinghyan (Chief Compiler), 1987. Lithospheric Dynamics Map of China and Adjacent Seas $(1: 4,000,000)$, and Explanatory Notes Geologieal Publishing House, China, 53p.

- Ma Zong jin and Xue Feng, 1983. Preliminary study of the distribution of focal depths in the Chinese continent and its layers being liable to occur eart hquakes Journal Earthquake Studies, p. $43-46$.

- Ma Zongjin, Fu Zhengxiang, Zhang Xizhen, Wang Chenming, Zhang Guoming and Liu Defu, 1984 Nine large eart hquakes of China, 1966-1976. Seismological Publishing House, 21 kp.

Minster, J.B. and Jordan, T.H., 1978. Present-day plate motions Journal of Geophysical Researeh, v. 83 , p. $5331-5345$

Molnar, P. and Tapponnier, P., 1975. Cenozoic tectonies of Asia: effects of a continental collision. Science, 4.189 , no. 4201, P. $419-426$.
Molnar, P. and Deng Qidong, 1984. Faulting associated with large earthquakes and the average rate of deformation in central and eastern Asia. Journal of Geophysical Research, v. 89, no. B 7, p. $6203-6227$.

Otsuki, K., 1985. Plate tectonics of eastern Eurasia in the light of fault systems Tohoku University Science Reports, 2nd Series (Geology), v, 55, no. 2, p. $141-251$.

Richantson, R.M., Solomon, S.C. and Sleep, N.H., 1979. Tectonic stress in the plates, Reviews of Geophysies and Space Physics, v. 17, no. 5, p. 981-1019.

Ron, H., Freund, R., Garfunkel, Z. and Nur, A., 1984. Block rotation by strike-slip faulting: struetural and paleomagnetic evidence. Journal of Geophsical Researeh, v. 89, no. B? p. $6256-6270$.

-Shen Xianjie, Deng Xioyue, Kang Wenhua, Li Delu, Bai Jachi and Wel Hungbin, 1985. Heat flow corrections and correction for the lake bottom temperature fluetuations to heat flow measured in South Xizang (Tibet). Acta Geophysica Sinica, v, 28, Supplement 1, p, 70-79.

Shi Zhengliang, Huan Wanlin, Lu Shoude and $Y_{a n}$ Jianquan, 1982. Characteristics of seismic activity in east and central Asia. Scientia Sinica, Series B, no. 9, P. $840-849$.

Shi Zhengliang, Huan Wenlin, $Y_{\text {an }}$ Jiaquan and Wang Suyun, 1985. Some features on the recent tectonic stress field and tectonic deformation field of China and its vicinity. Geophysical Research, v. 1, p. 103-129, China Academic Publishers

Song Zhonghe, An Changgiang, Chen Lihua and Qiu Zhirong, 1986, P-wave velocity of the upper mantle on the
D. $263-274$.

-Sun Wucheng, Li Songlin and Yang Yuchun, 1985. Preliminary study on crustal structures in the east of North China. Seismology and Geology, v, 7, no, $3, p_{1}, 1-12$.

Tapponnier, P., Peltzer, G. and Armijo, R., 1986. On the mechanics of the collision between Indie and Asia. In: Coward, M.P. et al., (eds), Collision Tectonics Geological Society Speciei Publication, no. 19, p. 115-157.

Turcotte, D.t. and Schubert, G. 1982, Geadynamies, Applications of Continuum Physies to Gec logical Problems. John Wiley, $450 \mathrm{p}$.

- Wang Suyun and Xu Zhonghuai, 1985. Seismo-tectonic stress field in East China. Acta Seismologica Sinica, v. 7, no. 1, p. 17-32.

Wei Menghua, Wang Qiming, Sti Zhihong, Yin Xiu-hua, Liu Zhanpo and Zhang Yumel, 1981. A preliminary study of the free-air gravimetric field in the Chinese continent. Seismology an Geology, v. 3, no. 3, p. $47-60$.

Wu Daning, Yu Huichuan, Han Zhujun and Zhou Chunping, 1987. Active tectonies in northwestern Yunnan and their formation mechanism, (to be published).

Vu, Francis T., 1979. Recent tectonics of Taiwan. Journal of Physies of the Earth, v. 26, P. $265 \sim 299$.

*Yan Jiaquan, Shi Zhengliang, Wang Suyun and Huan Wenlin, 1979. The regional characteristic of present-day tectonic stress field in China and adjacent region. Acta Seismologica Sinica, v. 1 no. 1, p. 9-24.

- Yin Xiuhua, Shi Zhihong, Liu Zhanpo and Zhang Yumel, 1980. The basic features of regional gravity field in Chinese continent. Seismology and Geology, v. 3, no. 4, p. 69-75.

Zonenshain, L.P, and Savostin, L.A., 1981. Geodynamies of the Baikal rift zone and plate tectonies of Asia. Tectonophysios, v, 76, no, 1-2, p. 1-45. 